Article

\title{
Design of Zeolite-Covalent Organic Frameworks for Methane Storage
}

\author{
Ha Huu Do ${ }^{1,2}$, Soo Young Kim ${ }^{3, * \mathbb{D}}$, Quyet Van Le ${ }^{4, *}$ a and Nguyen-Nguyen Pham-Tran ${ }^{1,5, *}$ \\ 1 Institute for Computational Science and Technology (ICST), Quang Trung Software City, \\ Ho Chi Minh City 700000, Vietnam; hadohuu1311@gmail.com \\ 2 School of Chemical Engineering and Materials Science, Chung-Ang University, 84 Heukseok-ro, Dongjak-gu, \\ Seoul 06974, Korea \\ 3 Department of Materials Science and Engineering, Korea University, 145 Anam-ro Seongbuk-gu, \\ Seoul 02841, Korea \\ 4 Institute of Research and Development, Duy Tan University, Da Nang 550000, Vietnam \\ 5 Faculty of Chemistry, University of Science, VNU-HCM, Ho Chi Minh City 700000, Vietnam \\ * Correspondence: sooyoungkim@korea.ac.kr (S.Y.K.); levanquyet@dtu.edu.vn (Q.V.L.); \\ ptnnguyen@hcmus.edu.vn (N.-N.P.-T.)
}

Received: 26 June 2020; Accepted: 24 July 2020; Published: 26 July 2020

check for updates

\begin{abstract}
A new type of zeolite-based covalent organic frameworks (ZCOFs) was designed under different topologies and linkers. In this study, the silicon atoms in zeolite structures were replaced by carbon atoms in thiophene, furan, and pyrrole linkers. Through the adoption of this strategy, 300 ZCOFs structures were constructed and simulated. Overall, the specific surface area of ZCOFs is in the range of $300-3500 \mathrm{~m}^{2} / \mathrm{g}$, whereas the pore size is distributed from 3 to $27 \AA$. Furthermore, the pore volume exhibits a wide range between 0.01 and $1.5 \mathrm{~cm}^{3} / \mathrm{g}$. Screening $300 \mathrm{ZCOFs}$ with the criteria towards methane storage, 11 preliminary structures were selected. In addition, the Grand Canonical Monte Carlo technique was utilized to evaluate the $\mathrm{CH}_{4}$ adsorption ability of ZCOFs in a pressure ranging from 1 to 85 bar at a temperature of $298 \mathrm{~K}$. The result reveals that two ZCOF structures: JST-S $183 v / v(65-5.8$ bar) and NPT-S $177 v / v$ (35-1 bar) are considered as potential adsorbents for methane storage. Furthermore, the thermodynamic stability of representative structures is also checked base on quantum mechanical calculations.
\end{abstract}

Keywords: ZCOFs; methane storage; porous materials; simulation; design

\section{Introduction}

Methane is known as the fundamental ingredient of natural gas which is found with oil fields in Earth's crust. Currently, methane is also exploited from methane hydrate, recognized as a promising resource to provide energy in the future. However, efficiency and safety are two critical criteria for methane storage that need to be addressed in practical applications. Therefore, a large number of studies have focused on methane storage with porous materials such as covalent organic frameworks (COFs), zeolitic imidazole frameworks, hydrogen-bonded organic frameworks, and metal-organic frameworks (MOFs) [1-6]. In 2006, ZIFs were firstly reported with various topologies such as sod, rho, and mer [7]. This study opened a new window for the synthesis of porous material as well as their applications. In addition, zeolite-like MOFs (ZMOFs) were also simulated and prepared with different zeolite frameworks $[8,9]$. For example, two anionic ZMOFs, including rho-ZMOF and sod-ZMOF were fabricated successfully by Liu et al. [8]. These materials have a high surface area which can provide exceptional gas adsorption such as $\mathrm{H}_{2}, \mathrm{CH}_{4}$, and $\mathrm{CO}_{2}$. Therefore, $\mathrm{ZCOFs}$ are evaluated as potential porous materials for gas storage. 
Over the past decade, COFs have become interesting materials in the porous material group due to their outstanding specific surface area. Similar to MOF, COFs have crystal structures with controllable pore sizes [10]. However, COFs have a definite advantage that they only contain non-metal elements such as $\mathrm{C}, \mathrm{Si}, \mathrm{B}, \mathrm{O}$, and $\mathrm{H}$. These elements were linked together by a vast number of covalent bonds to form COFs structures. In 2005, the first COF materials were synthesized by Yaghi et al., using the solvothermal method [10]. Later, many researchers tried to expand the ability to synthesize COFs in different ways [11]. Similar to MOFs, COFs have been scrutinized in a wide range of utilizations such as gas storage [12-16], catalysis $[17,18]$, and sensors $[19,20]$ due to their feature properties such as high thermal durability, large surface area, and low density [15]. For example, COF-108 displayed a very low density of $0.17 \mathrm{~g} \cdot \mathrm{cm}^{-3}$ which is lower than any reported materials [21-23]. COF-105 gave a high surface area of over $6000 \mathrm{~m}^{2} \cdot \mathrm{g}^{-1}$ [21]. The US Department of Energy (DOE) proposed a standard of the $\mathrm{CH}_{4}$ adsorption ability for porous materials to be $180 \mathrm{~V}(\mathrm{STP}) / \mathrm{V}$, (where STP is the standard temperature and pressure) [24]. On the theoretical study side, Goddard et al. successfully designed two materials with appropriate functional groups to enhance the methane storage properties of some COF materials [25]. That was, COF-103-Eth-trans and COF-102-Ant with methane adsorption capacity exceeding the target set by the DOE (Figure S1). Another group, Jing Hao Hu et al., modified COF-102 with a double halogen substitution [26]. Their simulation result shows that the methane adsorption capacity of COF-102-1,4-2I is $181 \mathrm{~V}$ (STP)/V. In addition, a few porous materials have been fabricated experimentally which surpassed the DOE standard, such as Ni-MOF-74 [27] (190 v(STP)/v) and PCN-14 [28] (220 v(STP)/v).

Recently, a new DOE target has been provided for methane storage to be $315 \mathrm{~cm}^{3} / \mathrm{cm}^{3}$ (at (35-1 bar) or (65-5.8 bar)) for the single crystal material $[29,30]$. To date, there was not any experimental $\mathrm{COFs}$, which can overcome the DOE target. Therefore, several efforts related to the porous materials were conducted to find outstanding candidates for methane storage. For instance, Zhao et al. used the various functional groups involving $-\mathrm{CF}_{3},-\mathrm{CH}_{3},-\mathrm{CN},-\mathrm{OCH}_{3},-\mathrm{CN},-\mathrm{Cl}, \mathrm{Br}, \mathrm{I}$, and $\mathrm{NH}_{2}$ to improve the methane adsorption ability of three-dimensional COFs [31]. The result indicated that COF-102-I exhibited the highest $\mathrm{CH}_{4}$ uptake among the modified materials. Martin et al. generated a large number of porous polymer networks ( 18,000 structures) for $\mathrm{CH}_{4}$ adsorption. However, only three structures achieved the $\mathrm{CH}_{4}$ adsorption of $180 \mathrm{~cm}^{3} / \mathrm{cm}^{3}$ [32]. This result implied that finding excellent materials for methane storage is a great challenge for scientists. Herein, under the support of computer tools, we proposed a strategy design of COF materials with different zeolite frameworks to find potential COF materials that are capable of methane storage reaching the DOE target. We also demonstrate the survival of selected COFs from rational design, which provides useful information for experimental studies.

\section{Design Strategy and Methodologies}

Figure 1 illustrates the designed strategy of the covalent organic framework from the zeolite frameworks. Replacing the silicon atom in 100 selected zeolite framework types by carbon from thiophene (Figure S2), furan, and pyrrole linkers, 300 ZCOF structures were constructed. Since the topology of ZCOFs is inherited by the zeolite framework types, we named the newly designed materials, such as YYY-S, YYY-O, and YYY-N. Therein, YYY stands for the framework type code of the zeolite, $-S$, $-\mathrm{O},-\mathrm{N}$ stand for thiophene, furan, and pyrrole, respectively. 

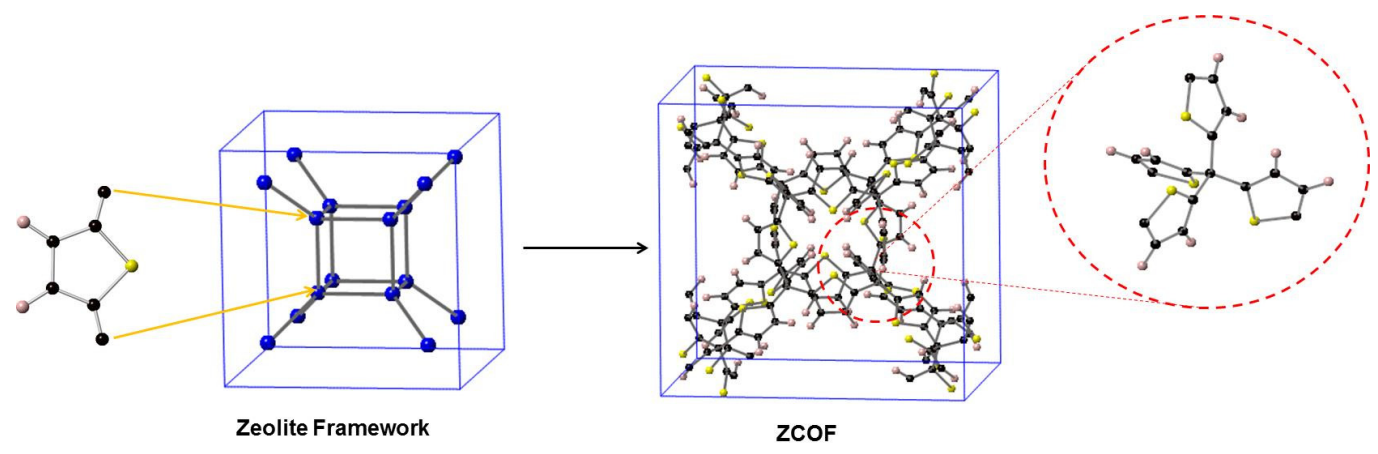

Figure 1. Graphical illustration of the design strategy for zeolite-based covalent organic frameworks (ZCOFs) materials. The spheres in black, pink, and yellow denote $\mathrm{C}, \mathrm{H}$, and $\mathrm{S}$ (or $\mathrm{O}, \mathrm{N}-\mathrm{H}$ ) atoms, respectively.

The ZCOF structures are built and optimized through the universal force field via forcite tools [33]. The pore diameter (Dpore), accessible surface area (Sacc), and pore volume (Vpore) are calculated by the $\mathrm{ZeO}++$ code. A spherical model with a radius of $1.8405 \AA$ was used to simulate the $\mathrm{N}_{2}$ molecule $[34,35]$.

All grand canonical Monte Carlo (GCMC) computations were conducted by utilizing the MUSIC code [36]. The potential energy between the $\mathrm{COF}-\mathrm{CH}_{4}$ and $\mathrm{CH}_{4}-\mathrm{CH}_{4}$ was obtained from van der Waals interactions since $\mathrm{CH}_{4}$ is the poor polar molecule. The $\mathrm{CH}_{4}$ molecule is simulated as a sphere with a kinetic diameter of $3.8 \AA$ [37]. Lennard-Jones potential was used with the parameters acquired from the transferable force fields (TraPPE) [38] for $\mathrm{CH}_{4}$ and Universal Force field for the atoms in the ZCOFs [33]. The distances are more considerable than $12.8 \AA$, not considered in this model. The parameters for interactions between the atoms of $\mathrm{ZCOFs}$ and $\mathrm{CH}_{4}$ molecules were estimated through the Lorentz-Berthelot rule [39]. In the simulation, a supercell $2 \times 2 \times 2$ of COF was kept rigid, $\mathrm{CH}_{4}$ was considered a 'spherical molecule'. For each pressure point, $15 \times 106$ Monte Carlo trial moves were performed. This technique has been successfully applied for adsorption studies, reported in the previous works [40]. The variables of force field for $\mathrm{ZCOFs}$ and $\mathrm{CH}_{4}$ are provided in Table 1 . The detailed parameters and structures of ZCOF were shown in Table S1 in the supplementary information.

Table 1. The parameters of force field for $\mathrm{ZCOF}$ and $\mathrm{CH}_{4}$.

\begin{tabular}{ccccc}
\hline Molecule & Atom & $\boldsymbol{\varepsilon} / \mathbf{k b}(\mathbf{K})$ & $\boldsymbol{\sigma}(\AA)$ & ref \\
\hline $\mathbf{C H}_{4}$ & - & 148.0 & 3.73 & {$[38]$} \\
& $\mathrm{C}$ & 52.8 & 3.43 & {$[33]$} \\
\multirow{2}{*}{ ZCOFs } & $\mathrm{H}$ & 22.1 & 2.57 & - \\
& $\mathrm{S}$ & 137.9 & 3.59 & - \\
& $\mathrm{O}$ & 30.2 & 3.12 & - \\
& $\mathrm{N}$ & 34.7 & 3.26 & - \\
\hline
\end{tabular}

Implementing the density functional theory (DFT) for periodic systems in CRYSTAL17 was used for the study of the structural stability of new ZCOFs [41,42]. Specifically, the calculations were executed with the exchange-correlation functional of Perdew-Burke-Ernzerhof (PBE), and a basic set of 6-31G functions for atoms in the ZCOF structures. The values of 0.00030 and 0.00045 are indications of the convergence criteria of force for a root-mean-square and maximum component of the gradient, respectively, whereas, the condition was set to $10^{-7}$ Hatrees during the geometry optimization for self-consistent total energy calculations (NPT-S, JST-S code). 


\section{Results and Discussion}

\subsection{Screening ZCOFs for Methane Storage}

Figure 2 provides information about Dpore, Sacc, and Vpore of 300 ZCOF structures. The pore sizes of these ZCOFs cover a range from 3 to $27 \AA$, and most ZCOFs have a pore size of about $8-14 \AA$, whereas the distribution of the surface area revealed that most ZCOFs exhibited the high surface area between 1000 and $2000 \mathrm{~m}^{2} / \mathrm{g}$ and extended to nearly $3500 \mathrm{~m}^{2} / \mathrm{g}$. This is well because the Sacc of zeolite is often lower than $900 \mathrm{~m}^{2} / \mathrm{g}$. Notably, RWY-N displayed the largest surface area of $3437 \mathrm{~m}^{2} / \mathrm{g}$ among 300 ZCOF materials. However, the pore volume of ZCOF is not much higher than that of zeolite and most are less than $1 \mathrm{~cm}^{3} / \mathrm{g}$.
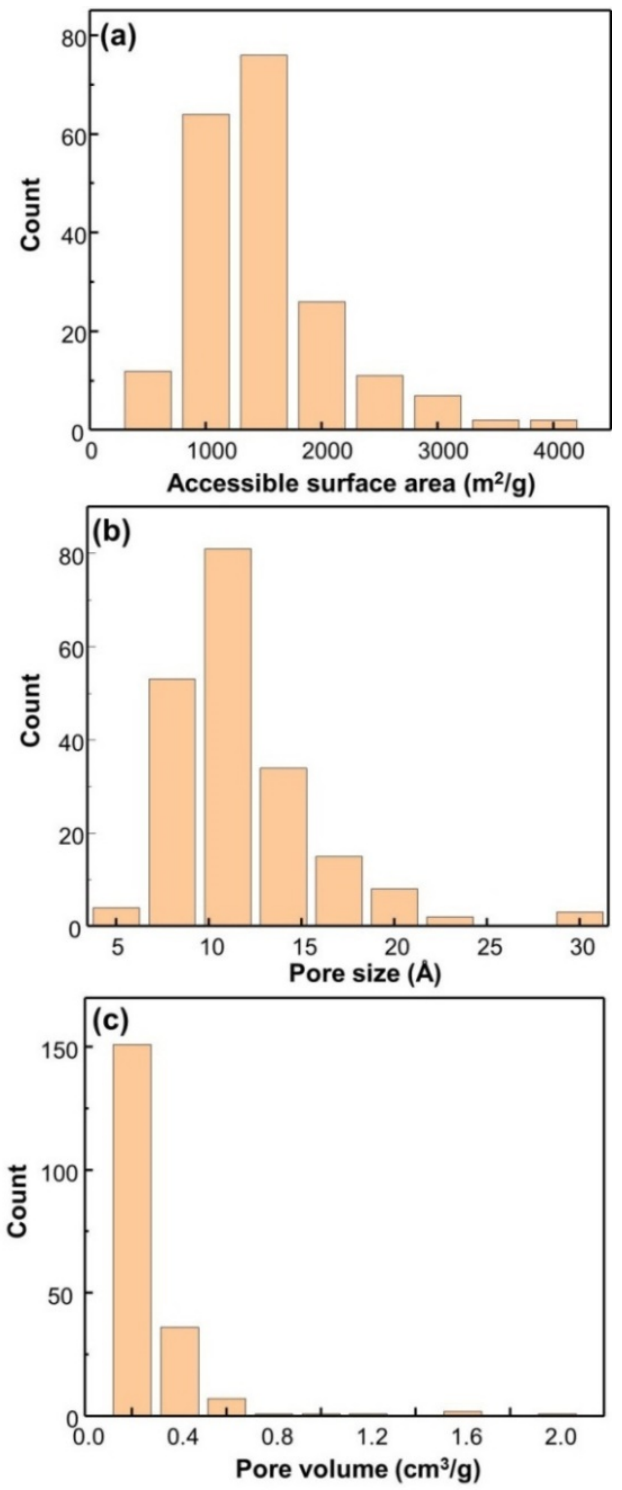

Figure 2. Statistical analysis of all 300 ZCOFs constructed: (a) Accessible surface area; (b) pore size; (c) pore volume.

Using the screening parameters for methane storage materials in the work of Martin et al. [32], such as Dpore $>10 \AA$, Sacc $>2000 \mathrm{~m}^{2} / \mathrm{g}$, and Vpore $>0.4 \mathrm{~cm}^{3} / \mathrm{g}$, a total of $11 \mathrm{ZCOF}$ candidates were selected through 300 designed ZCOFs. The parameters of 11 ZCOF structures are provided in Table 2. 
Table 2. The porous properties, total methane uptake, and delivery capacity of the 11 selected ZCOF structures.

\begin{tabular}{|c|c|c|c|c|c|c|c|}
\hline ZCOFs & $\begin{array}{c}\text { Sacc } \\
\left(\mathrm{m}^{2} / \mathrm{g}\right)\end{array}$ & $\begin{array}{l}\text { Dpore } \\
\text { (Å) }\end{array}$ & $\begin{array}{c}\text { Vpore } \\
\left(\mathrm{cm}^{3} / \mathrm{g}\right)\end{array}$ & $\begin{array}{c}\text { Total Uptake } \\
\text { at } 35 \mathrm{bar} \\
\left(\mathrm{cm}^{3} / \mathrm{cm}^{3}\right)\end{array}$ & $\begin{array}{c}\text { Delivery Capacity } \\
35-1 \mathrm{bar} \\
\left(\mathrm{cm}^{3} / \mathrm{cm}^{3}\right)\end{array}$ & $\begin{array}{l}\text { Total Uptake } \\
\text { at } 65 \mathrm{bar} \\
\left(\mathrm{cm}^{3} / \mathrm{cm}^{3}\right)\end{array}$ & $\begin{array}{l}\text { Delivery } \\
\text { Capacity } \\
65-5.8 \text { bar }\end{array}$ \\
\hline BOZ-S & 2579 & 16.1 & 0.516 & 191 & 174 & 227 & 152 \\
\hline JSR-N & 2865 & 12.8 & 0.543 & 197 & 174 & 231 & 150 \\
\hline JSR-O & 2702 & 12.4 & 0.489 & 187 & 170 & 221 & 151 \\
\hline JSR-S & 2480 & 13.6 & 0.612 & 179 & 168 & 220 & 164 \\
\hline JST-S & 2615 & 10.7 & 0.433 & 179 & 169 & 230 & 183 \\
\hline NPT-S & 2548 & 19.5 & 0.502 & 194 & 177 & 227 & 145 \\
\hline OBW-N & 2920 & 13.8 & 0.451 & 191 & 166 & 221 & 134 \\
\hline OBW-S & 2734 & 15.7 & 0.557 & 191 & 174 & 226 & 148 \\
\hline RWY-N & 3437 & 24.2 & 1.212 & 156 & 147 & 206 & 161 \\
\hline RWY-O & 3273 & 22.8 & 1.055 & 158 & 149 & 208 & 163 \\
\hline RWY-S & 3209 & 26.5 & 1.419 & 135 & 129 & 189 & 156 \\
\hline $\begin{array}{l}\text { Bulk } \\
\mathrm{CH}_{4}\end{array}$ & - & - & - & 34 & 33 & 66 & 61 \\
\hline
\end{tabular}

\subsection{Adsorption of $\mathrm{CH}_{4}$}

The $\mathrm{CH}_{4}$ adsorption capacity at $298 \mathrm{~K}$ for the 11 selected ZCOFs was illustrated in Figure 3. We realize that the adsorption isotherm of the selected ZCOFs is quite close together. Methane adsorption of most of the ZCOFs rapid growth in the range of 0-20 bar then increases slowly and reaches equilibrium at a pressure of about 60 bar. However, three ZCOF crystal structures: RWY-O, RWY-N, and RWY-S with an increasing pore diameter (as shown in Figure 4, Figure S3), have shown lower methane uptake compared to the other ZCOFs. This can be explained via their pore size, the ZCOF with a large pore size increases the distance of methane and active sites, leading to the weak interactions. Thus, the too-large pore diameter was not favorable in the methane storage application.
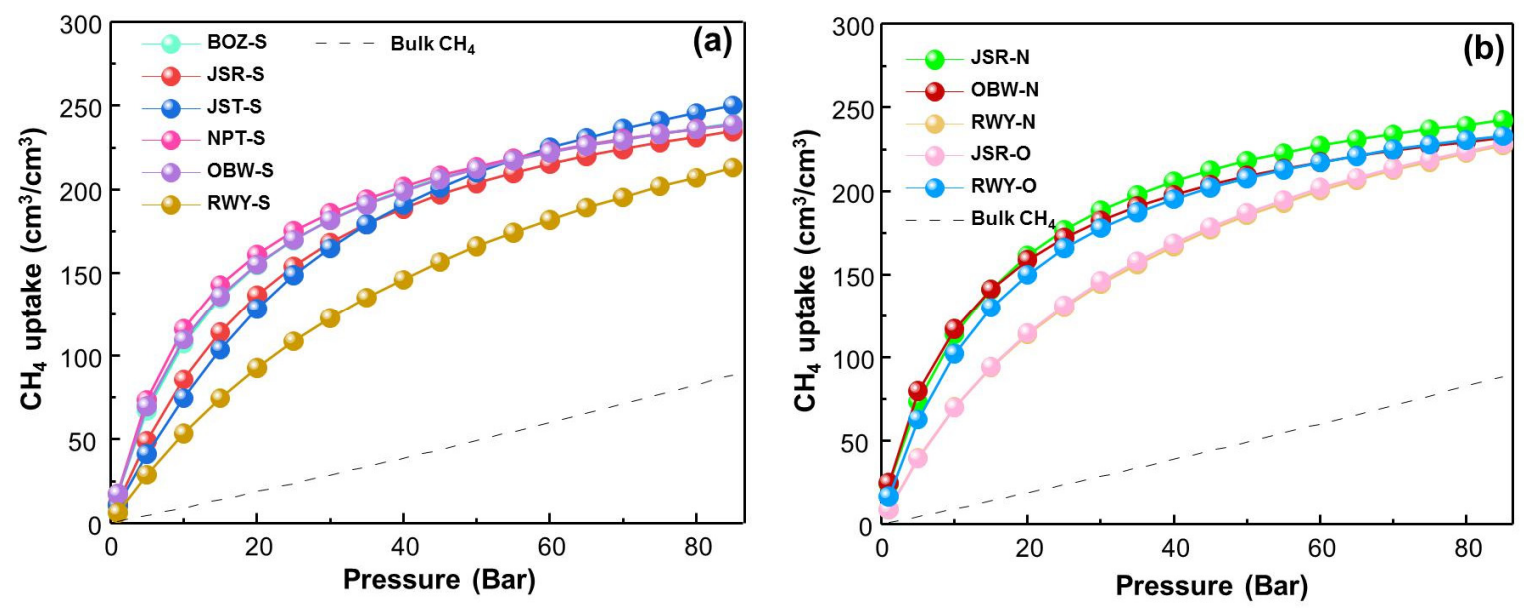

Figure 3. Isotherms of total $\mathrm{CH}_{4}$ adsorption in a pressure ranging from 1 to 85 bar at a temperature of $298 \mathrm{~K}$ of 11 ZCOFs. (a) XXX-S; (b) XXX-O and XXX-N. 


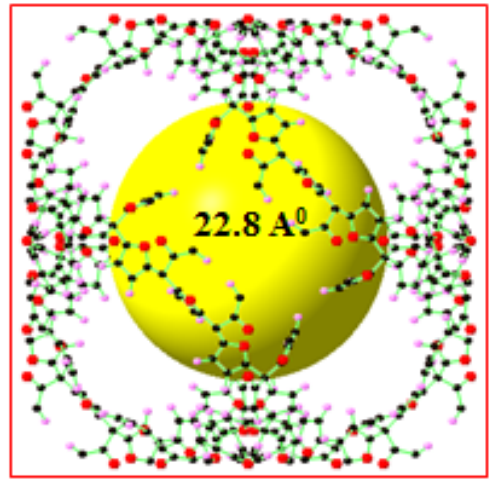

RWY-O

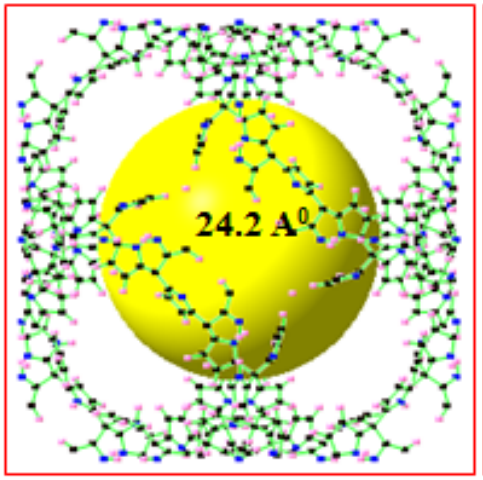

RWY-N

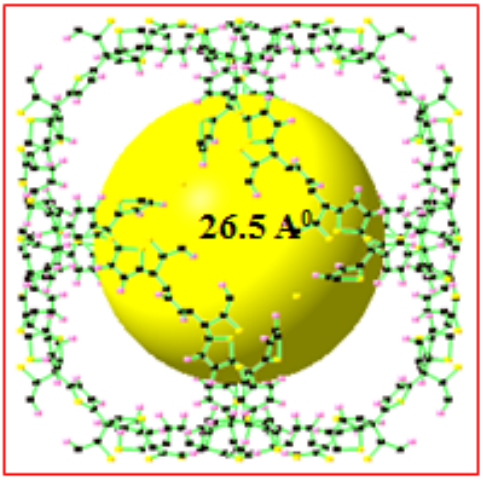

RWY-S

Figure 4. ZCOF crystal structures of RWY-O, RWY-N, and RWY-S. The spheres in black, pink, red, blue, and orange denote $\mathrm{C}, \mathrm{H}, \mathrm{O}, \mathrm{N}$, and $\mathrm{S}$ atoms, respectively. The yellow balls represent the pore size.

In 11 selected ZCOF structures, JSR-N has the highest adsorption capacity at 35 bar with 197 and $231(v / v)$ at 65 bar and followed by BOZ-S, OBW-S, JSR-O, and OBW-N. In addition, the bulk density of methane was also illustrated by a black dotted line for comparison purposes. It is clearly shown that $\mathrm{ZCOFs}$ are effective adsorbents for methane storage applications.

\subsection{Methane Delivery Capacity}

The methane delivery capacity of the ZCOF selected structures is calculated as follows [32]:

$$
\begin{gathered}
\text { DC (35-1) }=\text { the } \mathrm{CH}_{4} \text { adsorption at } 35 \text { bar }- \text { the } \mathrm{CH}_{4} \text { adsorption at } 1 \text { bar } \\
\text { DC }(65-5.8)=\text { the } \mathrm{CH}_{4} \text { adsorption at } 65 \text { bar }- \text { the } \mathrm{CH}_{4} \text { adsorption at } 5.8 \text { bar }
\end{gathered}
$$

Table 2 presents the delivery capacity of 11 ZCOF structures, which exhibited excellent performances for methane storage. In total, NPS-S and JST-S give the best methane uptake, as shown in Figure 5a. In particular, Figure 5b indicated that NPT-S gave the largest DC (35-1) of $177 \mathrm{~cm}^{3}$ STP $\left(\mathrm{CH}_{4}\right) / \mathrm{cm}^{3}$, while the largest DC (65-5.8) reached was $183 \mathrm{~cm}^{3} \mathrm{STP}\left(\mathrm{CH}_{4}\right) / \mathrm{cm}^{3}$, for the JST-S structure. The results are comparable with the previous studies and DOE 2000 target for methane storage $\left(180 \mathrm{~cm}^{3}\right.$ STP $\left./ \mathrm{cm}^{3}\right)$, as displayed in Table 3 [43]. This finding was attributed to the appropriate porous parameters for methane storage, as reported in Martin's study [32]. Notably, JST-S has a pore size of $10.7 \AA$, whereas NPT-S gave a pore diameter of $19.5 \AA$, as illustrated in Figure 6 . 

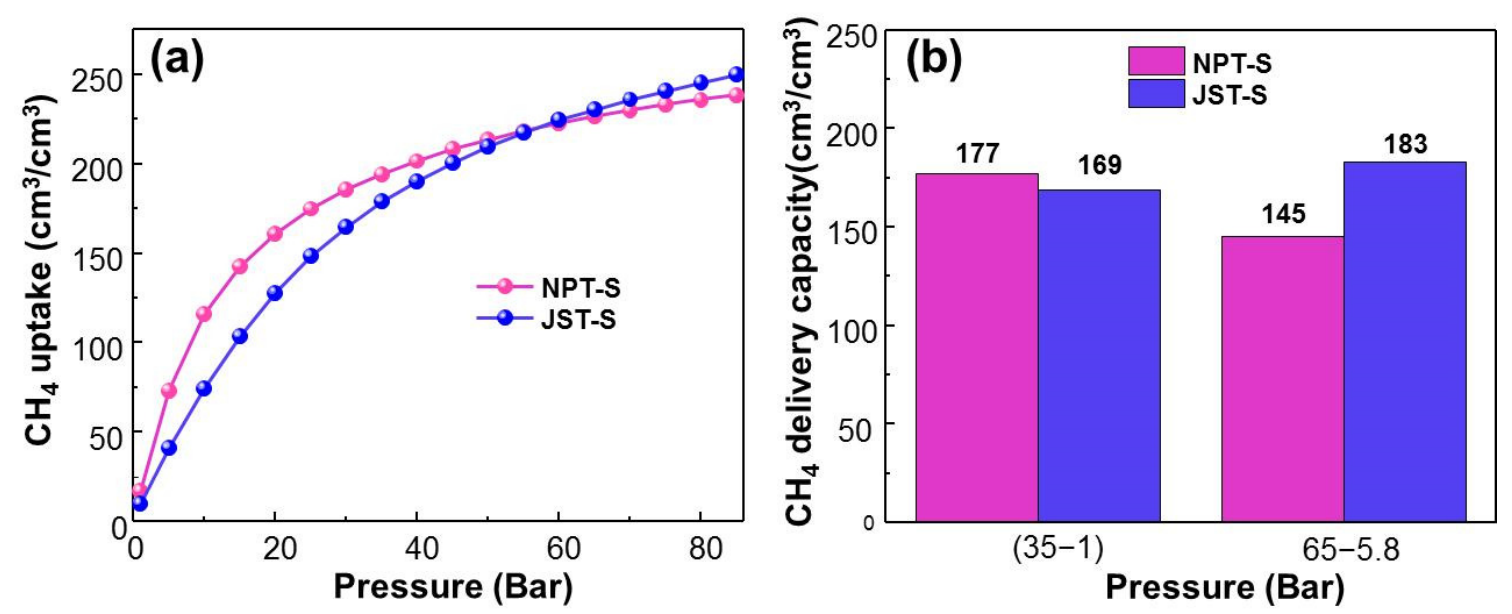

Figure 5. (a) Isotherms of total volumetric $\mathrm{CH}_{4}$ uptake at $298 \mathrm{~K}$ from 0 to 85 bar, and (b) $\mathrm{CH}_{4}$ delivery capacity of NPT-S and JST-S.

Table 3. Comparison of the methane uptake of NPT-S and the other COFs at 35 bar and $298 \mathrm{~K}$.

\begin{tabular}{|c|c|c|c|c|c|c|}
\hline ZCOFs & $\begin{array}{c}\text { Sacc } \\
\left(\mathrm{m}^{2} / \mathrm{g}\right)\end{array}$ & $\begin{array}{l}\text { Dpore } \\
(\AA)\end{array}$ & $\begin{array}{c}\text { Vpore } \\
\left(\mathrm{cm}^{3} / \mathrm{g}\right)\end{array}$ & $\begin{array}{c}\mathrm{CH}_{4} \text { Uptake } \\
\left(\mathrm{cm}^{3} / \mathrm{cm}^{3}\right)\end{array}$ & $\begin{array}{c}\mathrm{CH}_{4} \text { Delivery } \\
\left(\mathrm{cm}^{3} / \mathrm{cm}^{3}\right)\end{array}$ & Ref \\
\hline COF-102-Ant & 2720 & - & 0.75 & 215 & 180 & [25] \\
\hline COF-103-Eth-trans & 4920 & - & 1.36 & 206 & 192 & [25] \\
\hline COF-102-1,4-2I & - & - & - & - & 181 & [26] \\
\hline COF-102-I & - & - & - & 176 & 169 & [31] \\
\hline COF-102-Cl & - & - & - & 169 & 165 & [31] \\
\hline COF-1 & 750 & 9 & 0.30 & 55 & - & [44] \\
\hline COF-5 & 1670 & 27 & 1.07 & 73 & - & [44] \\
\hline COF-6 & 750 & 9 & 0.32 & 101 & - & [44] \\
\hline COF-8 & 1350 & 16 & 0.69 & 85 & - & [44] \\
\hline COF-10 & 1760 & 32 & 1.44 & 53 & - & [44] \\
\hline COF-102 & 3620 & 12 & 1.55 & 113 & - & [44] \\
\hline COF-103 & 3530 & 12 & 1.54 & 105 & - & [44] \\
\hline NPT-S & 2548 & 19.5 & 0.502 & 194 & 177 & This work \\
\hline
\end{tabular}

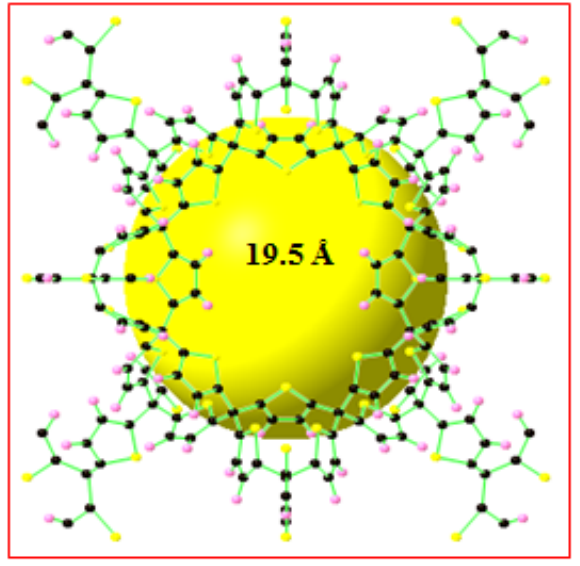

NPT-S

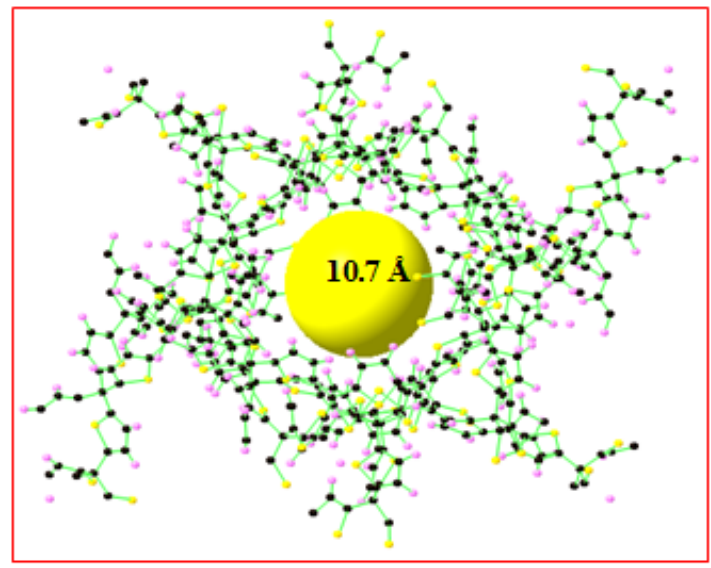

JST-S

Figure 6. Two ZCOF structures: NPT-S and JST-S. The spheres in black, pink, and orange denote C, H, and $\mathrm{S}$ atoms, respectively. The yellow balls represent the pore size.

\section{4. $\mathrm{CH}_{4}$ Adsorption Sites}

To date, only several studies provide the mechanism for $\mathrm{CH}_{4}$ adsorption in porous materials. For instance, Mendoza-Cortes et al. indicated that the various 3D-COFs, including COF-105, COF-103, 
and COF-102, contains the adsorption centers on the surface of the benzene ring [5]. In this work, we propose that the $\mathrm{CH}_{4}$ adsorption sites can be on the face of the thiophene, furane, and pyrrole rings, as illustrated in Figure 7.
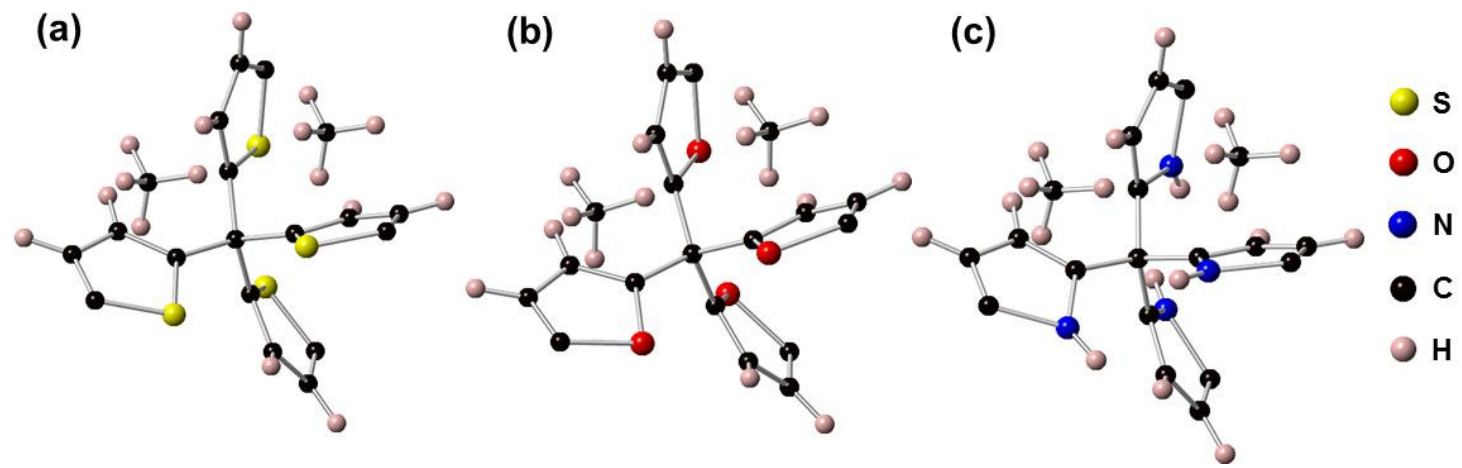

Figure 7. The adsorption of $\mathrm{CH}_{4}$ on the surface of thiophene (a), furane (b), and pyrrole rings (c) for YYY-S, YYY-O, and YYY-N, respectively.

\subsection{The Formation Energy of JST-S and NPT-S}

The heat of formation is a powerful means to predict the thermodynamic stability of any structures. The enthalpy of formation with a negative value indicates that the considered compound is stable in terms of thermodynamic. In this research, the reaction enthalpy for JST-S and NPT-S generation was determined from the change in the total enthalpy between the products and reactants. They were calculated from reaction (3) and (4):

$$
\begin{gathered}
18 \text { Cgraphite }+4 \mathrm{H}_{2}+1 / 2 \mathrm{~S}_{8} \rightarrow \mathrm{C}_{18} \mathrm{H}_{8} \mathrm{~S}_{4} \text { (JST-S) } \\
54 \text { Cgraphite }+12 \mathrm{H}_{2}+3 / 2 \mathrm{~S}_{8} \rightarrow \mathrm{C}_{54} \mathrm{H}_{24} \mathrm{~S}_{12} \text { (NPT-S) }
\end{gathered}
$$

The reactants selected to be the best stable state in nature, include graphite, hydrogen gas, and sulfur (rhombic). Therefore, their standard enthalpy of formations is zero. The negative quantities exhibited in Table 4, implied that JST-S and NPT-S could be synthesized in the experiment.

Table 4. Optimized crystal structure lattice parameters.

\begin{tabular}{ccccc}
\hline ZCOF & Symmetry & Atom/Cell & Lattice Parameter $(\AA)$ & $\Delta \mathbf{H}(\mathbf{k J} / \mathbf{m o l})$ \\
\hline JST-S & Pa-3 & 720 & 27.3204 & $-34,823 \times 10^{3}$ \\
NPT-S & Pm-3 & 540 & 25.0125 & $-8705 \times 10^{3}$ \\
\hline
\end{tabular}

\section{Conclusions}

In summary, we have shown the design strategy of a new covalent organic framework by using carbon to replace silicon in zeolite through thiophene, furan, and pyrrole linkers, named so we can obtain 300 ZCOF structures with 100 topologies of zeolite. The typical porous parameters, including the accessible surface area, pore size, and pore volume were analyzed to evaluate the quality of $\mathrm{ZCOFs}$ material through the Zeo++ software. The results reveal that the surface area of ZCOFs is larger than that of zeolites, which is favorable for methane storage. Notably, RWY-N displayed the largest accessible surface area of $3437 \mathrm{~m}^{2} / \mathrm{g}$, proposed for the promising material in gas storage applications. Among 300 ZCOFs materials, eleven optimal structures involving BOZ-S, JSR-N, JSR-O, JSR-S, JST-S, NPT-S, OBW-N, OBW-S, RWY-N, RWY-O, and RWY-S exhibited good methane adsorption ability. In particular, NPT-S displayed the largest DC (35-1) of $177 \mathrm{~cm}^{3}$ STP $\left(\mathrm{CH}_{4}\right) / \mathrm{cm}^{3}$, whereas JST-S exhibited the best DC (65-5.8) of $183 \mathrm{~cm}^{3}$ STP $\left(\mathrm{CH}_{4}\right) / \mathrm{cm}^{3}$. This finding can be comparable to the old DOE standard. In addition, the calculation of enthalpy of NPT-S and JST-S was also implemented by 
the DFT method, showing negative values. This result implied that these structures could be prepared in the experimental study.

Supplementary Materials: The following are available online at http://www.mdpi.com/1996-1944/13/15/3322/s1, Figure S1: Design strategy of ZCOFs with thiophene linker. The spheres in black, pink, yellow denote C, H, and S atoms, respectively, Figure S2: Isotherms of total volumetric $\mathrm{CH}_{4}$ uptake at $298 \mathrm{~K}$ from 0 to 85 bar of (a) RWY-X, and (b) JRN-X (X = N, O, S), Figure S3: (a) ctn and bor topologies, (b) the building blocks for designing new COFs, (c) the reactions from various reactants to created new COFs, Table S1: The parameter of $300 \mathrm{Z}-\mathrm{COF}$ structures, Computer Code: NPT-S, JST-S.

Author Contributions: H.H.D. performed the design of ZCOFs materials and most of the theoretical simulation; S.Y.K. and N.-N.P.-T. supervised the design and computational results; Q.V.L. developed the idea and prepared the manuscripts. All authors were concerned with drafting the manuscript. All authors have read and agreed to the published version of the manuscript.

Funding: This research was funded by The Institute for Computational Science and Technology (ICST), Ho Chi Minh City.

Acknowledgments: We gratefully acknowledge the Center for Computational Materials Science, Institute for Materials Research, Tohoku University for the use of MASAMUNE-IMR (project number: 19S0503), and The Institute for Computational Science and Technology (ICST), Ho Chi Minh City for research funding.

Conflicts of Interest: The authors declare no conflict of interest.

\section{References}

1. Cote, A.P.; El-Kaderi, H.M.; Furukawa, H.; Hunt, J.R.; Yaghi, O.M. Reticular synthesis of microporous and mesoporous 2D covalent organic frameworks. J. Am. Chem. Soc. 2007, 129, 12914-12915. [CrossRef] [PubMed]

2. Li, H.; Eddaoudi, M.; O'Keeffe, M.; Yaghi, O.M. Design and synthesis of an exceptionally stable and highly porous metal-organic framework. Nature 1999, 402, 276-279. [CrossRef]

3. Eddaoudi, M.; Kim, J.; Rosi, N.; Vodak, D.; Wachter, J.; O’Keeffe, M.; Yaghi, O.M. Systematic design of pore size and functionality in isoreticular MOFs and their application in methane storage. Science 2002, 295, 469-472. [CrossRef] [PubMed]

4. Düren, T.; Sarkisov, L.; Yaghi, O.M.; Snurr, R.Q. Design of new materials for methane storage. Langmuir 2004, 20, 2683-2689. [CrossRef]

5. Mendoza-Cortés, J.L.; Han, S.S.; Furukawa, H.; Yaghi, O.M.; Goddard III, W.A. Adsorption mechanism and uptake of methane in covalent organic frameworks: Theory and experiment. J. Phys. Chem. A 2010, 114, 10824-10833. [CrossRef]

6. Lin, R.-B.; He, Y.; Li, P.; Wang, H.; Zhou, W.; Chen, B. Multifunctional porous hydrogen-bonded organic framework materials. Chem. Soc. Rev. 2019, 48, 1362-1389. [CrossRef]

7. Park, K.S.; Ni, Z.; Côté, A.P.; Choi, J.Y.; Huang, R.; Uribe-Romo, F.J.; Chae, H.K.; O’Keeffe, M.; Yaghi, O.M. Exceptional chemical and thermal stability of zeolitic imidazolate frameworks. Proc. Natl. Acad. Sci. USA 2006, 103, 10186-10191. [CrossRef]

8. Liu, Y.; Kravtsov, V.C.; Larsen, R.; Eddaoudi, M. Molecular building blocks approach to the assembly of zeolite-like metal-organic frameworks (ZMOFs) with extra-large cavities. Chem. Commun. 2006, 1488-1490. [CrossRef]

9. Eddaoudi, M.; Sava, D.F.; Eubank, J.F.; Adil, K.; Guillerm, V. Zeolite-like metal-organic frameworks (ZMOFs): Design, synthesis, and properties. Chem. Soc. Rev. 2015, 44, 228-249. [CrossRef]

10. Cote, A.P.; Benin, A.I.; Ockwig, N.W.; O’Keeffe, M.; Matzger, A.J.; Yaghi, O.M. Porous, crystalline, covalent organic frameworks. Science 2005, 310, 1166-1170. [CrossRef]

11. Dogru, M.; Sonnauer, A.; Gavryushin, A.; Knochel, P.; Bein, T. A covalent organic framework with $4 \mathrm{~nm}$ open pores. Chem. Commun. 2011, 47, 1707-1709. [CrossRef] [PubMed]

12. Wu, J.; Zhou, J.; Wang, W.; Wang, H. Progress in Synthesis and Application of Covalent Organic Frameworks. Ekoloji 2019, 28, 4369-4378.

13. Guan, X.; Chen, F.; Fang, Q.; Qiu, S. Design and applications of three dimensional covalent organic frameworks. Chem. Soc. Rev. 2020, 49, 1357-1384. [CrossRef] [PubMed]

14. Cao, S.; Li, B.; Zhu, R.; Pang, H. Design and synthesis of covalent organic frameworks towards energy and environment fields. Chem. Eng. J. 2019, 355, 602-623. [CrossRef] 
15. Song, Y.; Sun, Q.; Aguila, B.; Ma, S. Opportunities of covalent organic frameworks for advanced applications. Adv. Sci. 2019, 6, 1801410. [CrossRef] [PubMed]

16. Tong, M.; Lan, Y.; Qin, Z.; Zhong, C. Computation-ready, experimental covalent organic framework for methane delivery: Screening and material design. J. Phys. Chem. C 2018, 122, 13009-13016. [CrossRef]

17. Sharma, R.K.; Yadav, P.; Yadav, M.; Gupta, R.; Rana, P.; Srivastava, A.; Zbořil, R.; Varma, R.S.; Antonietti, M.; Gawande, M.B. Recent development of covalent organic frameworks (COFs): Synthesis and catalytic (organic-electro-photo) applications. Mater. Horiz. 2020, 7, 411-454. [CrossRef]

18. Liu, J.; Wang, N.; Ma, L. Recent Advances in Covalent Organic Frameworks for Catalysis. Chem. Asian J. 2019, 15, 338-351. [CrossRef]

19. Ascherl, L.; Evans, E.W.; Gorman, J.; Orsborne, S.; Bessinger, D.; Bein, T.; Friend, R.H.; Auras, F. Perylene-Based Covalent Organic Frameworks for Acid Vapor Sensing. J. Am. Chem. Soc. 2019, 141, 15693-15699. [CrossRef]

20. Gao, Q.; Li, X.; Ning, G.-H.; Leng, K.; Tian, B.; Liu, C.; Tang, W.; Xu, H.-S.; Loh, K.P. Highly photoluminescent two-dimensional imine-based covalent organic frameworks for chemical sensing. Chem. Commun. 2018, 54, 2349-2352. [CrossRef]

21. El-Kaderi, H.M.; Hunt, J.R.; Mendoza-Cortés, J.L.; Côté, A.P.; Taylor, R.E.; O’Keeffe, M.; Yaghi, O.M. Designed synthesis of 3D covalent organic frameworks. Science 2007, 316, 268-272. [CrossRef] [PubMed]

22. Hunt, J.R.; Doonan, C.J.; LeVangie, J.D.; Côté, A.P.; Yaghi, O.M. Reticular synthesis of covalent organic borosilicate frameworks. J. Am. Chem. Soc. 2008, 130, 11872-11873. [CrossRef] [PubMed]

23. Furukawa, H.; Ko, N.; Go, Y.B.; Aratani, N.; Choi, S.B.; Choi, E.; Yazaydin, A.Ö.; Snurr, R.Q.; O’Keeffe, M.; Kim, J. Ultrahigh porosity in metal-organic frameworks. Science 2010, 329, 424-428. [CrossRef] [PubMed]

24. Burchell, T.; Rogers, M. Low pressure storage of natural gas for vehicular applications. SAE Trans. 2000, 109, 2242-2246.

25. Mendoza-Cortes, J.L.; Pascal, T.A.; Goddard III, W.A. Design of covalent organic frameworks for methane storage. J. Phys. Chem. A 2011, 115, 13852-13857. [CrossRef] [PubMed]

26. Hu, J.; Zhao, J.; Yan, T. Methane uptakes in covalent organic frameworks with double halogen substitution. J. Phys. Chem. C 2015, 119, 2010-2014. [CrossRef]

27. Wu, H.; Zhou, W.; Yildirim, T. High-capacity methane storage in metal-organic frameworks M2 (dhtp): The important role of open metal sites. J. Am. Chem. Soc. 2009, 131, 4995-5000. [CrossRef]

28. Ma, S.; Sun, D.; Simmons, J.M.; Collier, C.D.; Yuan, D.; Zhou, H.-C. Metal-organic framework from an anthracene derivative containing nanoscopic cages exhibiting high methane uptake. J. Am. Chem. Soc. 2008, 130, 1012-1016. [CrossRef]

29. Konstas, K.; Osl, T.; Yang, Y.; Batten, M.; Burke, N.; Hill, A.J.; Hill, M.R. Methane storage in metal organic frameworks. J. Mater. Chem 2012, 22, 16698-16708. [CrossRef]

30. Schoedel, A.; Ji, Z.; Yaghi, O.M. The role of metal-organic frameworks in a carbon-neutral energy cycle. Nat. Energy 2016, 1, 1-13. [CrossRef]

31. Zhao, J.; Yan, T. Effects of substituent groups on methane adsorption in covalent organic frameworks. RSC Adv. 2014, 4, 15542-15551. [CrossRef]

32. Martin, R.L.; Simon, C.M.; Smit, B.; Haranczyk, M. In silico design of porous polymer networks: High-throughput screening for methane storage materials. J. Am. Chem. Soc. 2014, 136, 5006-5022. [CrossRef]

33. Rappé, A.K.; Casewit, C.J.; Colwell, K.; Goddard III, W.A.; Skiff, W.M. UFF, a full periodic table force field for molecular mechanics and molecular dynamics simulations. J. Am. Chem. Soc. 1992, 114, 10024-10035. [CrossRef]

34. Willems, T.F.; Rycroft, C.H.; Kazi, M.; Meza, J.C.; Haranczyk, M. Algorithms and tools for high-throughput geometry-based analysis of crystalline porous materials. Microporous Mesoporous Mater. 2012, 149, $134-141$. [CrossRef]

35. Düren, T.; Millange, F.; Férey, G.; Walton, K.S.; Snurr, R.Q. Calculating geometric surface areas as a characterization tool for metal- organic frameworks. J. Phys. Chem. C 2007, 111, 15350-15356. [CrossRef]

36. Gupta, A.; Chempath, S.; Sanborn, M.J.; Clark, L.A.; Snurr, R.Q. Object-oriented programming paradigms for molecular modeling. Mol. Simul 2003, 29, 29-46. [CrossRef]

37. Yu, S.; Bo, J.; Wu, L. Molecular simulation of $\mathrm{CH} 4 / \mathrm{CO} 2 / \mathrm{H} 2 \mathrm{O}$ competitive adsorption on low rank coal vitrinite. Phys. Chem. Chem. Phys. 2017, 19, 17773-17788. [CrossRef] 
38. Martin, M.G.; Siepmann, J.I. Transferable potentials for phase equilibria. 1. United-atom description of n-alkanes. J. Phys. Chem. B 1998, 102, 2569-2577.

39. Zarkova, L.; Hohm, U.; Damyanova, M. Comparison of Lorentz-Berthelot and Tang-Toennies Mixing Rules Using an Isotropic Temperature-Dependent Potential Applied to the Thermophysical Properties of Binary Gas Mixtures of CH4, CF4, SF6, and C(CH3)4 with Ar, Kr, and Xe. Int. J. Thermophys. 2004, 25, 1775-1798. [CrossRef]

40. Düren, T.; Bae, Y.-S.; Snurr, R.Q. Using molecular simulation to characterise metal-organic frameworks for adsorption applications. Chem. Soc. Rev. 2009, 38, 1237-1247. [CrossRef]

41. Pascale, F.; Zicovich-Wilson, C.M.; Orlando, R.; Roetti, C.; Ugliengo, P.; Dovesi, R. Vibration frequencies of Mg3Al2Si3O12 pyrope. An ab initio study with the CRYSTAL code. J. Phys. Chem. B 2005, 109, 6146-6152. [PubMed]

42. Pham, H.Q.; Mai, T.; Pham-Tran, N.-N.; Kawazoe, Y.; Mizuseki, H.; Nguyen-Manh, D. Engineering of band gap in metal-organic frameworks by functionalizing organic linker: A systematic density functional theory investigation. J. Phys. Chem. C 2014, 118, 4567-4577. [CrossRef]

43. Li, B.; Wen, H.-M.; Zhou, W.; Xu, J.Q.; Chen, B. Porous metal-organic frameworks: Promising materials for methane storage. Chem 2016, 1,557-580. [CrossRef]

44. Furukawa, H.; Yaghi, O.M. Storage of hydrogen, methane, and carbon dioxide in highly porous covalent organic frameworks for clean energy applications. J. Am. Chem. Soc. 2009, 131, 8875-8883. [CrossRef]

(C) 2020 by the authors. Licensee MDPI, Basel, Switzerland. This article is an open access article distributed under the terms and conditions of the Creative Commons Attribution (CC BY) license (http://creativecommons.org/licenses/by/4.0/). 